BIOMEDICAL AND BIOSOCIAL ANTHROPOLOGY
$\begin{gathered}\text { Official Journal of the International Academy } \\ \text { of Integrative Anthropology } \\ \text { journal homepage: http://bba-journal.com }\end{gathered}$

\title{
Correlations of basal cranial structures characteristics determined by Bjork and Jarabak methods with teleradiographic parameters of the upper and lower jaws and tooth location in young men and young women with orthognathic occlusion

\author{
Vakhovskyi V. V., Shinkaruk-Dykovytska M. M., Pogorila A. V., Likhitskyi O. O., Gunas I. V.
}

National Pirogov Memorial Medical University, Vinnytsya, Ukraine

ARTICLE INFO The widespread use of metho

Received: 11 November 2020

Accepted: 11 December 2020

UDC: $616.314 .26-053.7-073.75$

CORRESPONDING AUTHOR

e-mail: vitalyvahovsky@gmail.com Vakhovskyi V. V.
The widespread use of methods of cephalometric analysis in practical orthodontics requires the adaptation of normative indicators for members of the local ethnic group. It is also important to study the relationships between cranial and odontometric parameters to understand the effects of these components on each other. The aim of the study was to establish the peculiarities of correlations between the characteristics of basal cranial structures determined by Bjork and Jarabak methods with teleradiographic parameters of the upper and lower jaws and the location of teeth in Ukrainian young men and young women with orthognathic occlusion. Teleradiography was performed in the mode of cephalometric examination of 49 young men (aged 17 to 21 years) and 76 young women (aged 16 to 20 years) who had a physiological bite as close as possible to orthognathic. Cephalometric analysis according to modifications of Jarabak J. R. - Roth-Jarabak and Bjork A. - CFT-Bjork methods, performed using OnyxCeph ${ }^{3} \mathrm{TM}$ software, 3DPro version, Image Instruments GmbH, Germany (software license № URSQ-1799). All indicators were divided into three groups according to Dmitriev M. O. (2017): the first group included metric characteristics of the skull, which are used as basic indicators in the methods of cephalometric analysis; to the second group - dental-maxillary in which the skeleton has already been formed and which surgical methods can change the length, width, angles and positions of the upper and lower jaws; to the third group - indicators that actually characterize the position of each individual tooth relative to each other, cranial structures and the profile of the soft tissues of the face. Correlation assessment was performed in the license package "Statistica 6.0" using the non-parametric Spearman method. As a result of the conducted researches in Ukrainian young men and young women with orthognathic occlusion the peculiarities of multiple correlations of characteristics of basal cranial structures determined by CFT-Bjork and Roth-Jarabak methods with teleradiographic parameters of upper and lower jaws and tooth location were established. Both the CFT-Bjork method and the Roth-Jarabak method have more reliable correlations in both young men and young women between the first and second groups $(23.3 \%$ for young men and $50.0 \%$ for young women for CFT-Bjork and $48.4 \%$ for young men and $41.1 \%$ for young women according to Roth-Jarabak) than between the indicators of the first and third groups (respectively $12.8 \%$ for young men and $7.7 \%$ for young women for CFT-Bjork and $22.5 \%$ for young men and $12.5 \%$ for young women for Roth-Jarabak). The expressed manifestations of sexual dimorphism of the received correlations between the indicators defined by CFT-Bjork and Roth-Jarabak methods both on quantity and force, and in some cases on a direction of correlations are established.

Keywords: teleradiography, cephalometric analysis by Jarabak and Bjork methods, correlations, Ukrainian young men and young women with orthognathic occlusion.

\section{Introduction}

The rapid development of orthodontics, which takes place both in Ukraine and abroad, is a logical consequence

of the rapid spread of anomalies of the dental and maxillofacial system. For example, an analysis of 878 
orthopantomograms at the Jeddah Dental Clinic (Saudi Arabia) showed that $45.1 \%$ of patients had at least one dental abnormality. Among the anomalies such pathologies as congenital absence of teeth $(25.7 \%)$, retinal detachment $(21.1 \%)$ prevailed; curvatures of tooth roots $(1.1 \%)$ and excess teeth $(0.3 \%)$ were less common [1].

Dental examination of 25,186 Italians found 61 posterior excess teeth in 45 people. The frequency of detection of this phenomenon was higher in men (ratio of men and women $2.5: 1$ ). In $62.3 \%$ this pathology was found on the upper jaw [8]. In another study conducted in Italy on a sample of 4006 people, data analysis showed that the prevalence of agenesis was $9 \%$. The most common was agenesis of the second premolars on the mandible $(20.3 \%$ in men and $18.1 \%$ in women). Absence of one to five teeth was observed in $8.6 \%$ of subjects [13].

In Turkey, the prevalence of dental anomalies among children was $2.0 \%$. As in previous studies, the prevalence of abnormalities was higher in boys than in girls [16]. A survey of 2,469 children in Nitte, India, found that the prevalence of hypodontia was $0.32 \%$ and that of excess teeth was $0.24 \%$.

In another study conducted in India, the analysis of the obtained data showed that $27.7 \%$ of the subjects had at least one odontological anomaly. Hypodontia, microdontia and hyperdontia were most frequently detected (10.4\%, $7.7 \%$ and $6.3 \%$, respectively) [29].

Thus, there was a need to find and implement new diagnostic and therapeutic methods. The teleradiographic method of research deserves special attention, which considers cranial and dental-maxillary structures as one complex, which can also affect each other [2]. Numerous methods of analysis have been proposed by leading scientists in the field of odontology for the correct interpretation of the obtained data, each of which has its advantages and disadvantages, therefore the authors often consider several methods in their research combining their indicators [22, 25].

However, the results of studies conducted by domestic researchers have shown that the methods of cephalometric analysis require adaptation for the Ukrainian population considering regional affiliation, gender and age [11, 14, 21, 27].

The aim of the study was to establish the peculiarities of correlations between the characteristics of basal cranial structures determined by Bjork and Jarabak methods with teleradiographic parameters of the upper and lower jaws and the location of teeth in Ukrainian young men and young women with orthognathic occlusion.

\section{Materials and methods}

Teleradiography in the mode of cephalometric examination was performed using a dental cone-beam tomograph Veraviewepocs 3D Morita (Japan) for 49 young men (YM) (aged 17 to 21 years) and 76 young women (YW) (aged 16 to 20 years) who had a physiological bite as close as possible to orthognathic (further orthognathic) which is determined by 11 points by Bushan M. G. and others. [6]. Cephalometric analysis according to modifications of the methods Jarabak J. R. [15] - Roth-Jarabak and Bjork A. [5] - CFT-Bjork, performed using OnyxCeph ${ }^{3 \mathrm{TM}}$ software, 3DPro version, Image Instruments $\mathrm{GmbH}$, Germany (software license № URSQ -1799).

Cephalometric points were determined according to the recommendations of Phulari B. S. [23] and Doroshenko S. I. and Kulginsky E. A. [12].

The main cephalometric points and measurements according to the CFT-Bjork method:

distance li-ls (known as Overbite by CFT-Bjork) - the distance from the point Is to li in the vertical plane, characterizes the inter-cut overlap in the vertical plane $(\mathrm{mm})$; distance li-NCL (Lower Lip Protrusion, also known as Li-NsPog' by Roth-Jarabak) - the distance from the point Li to the line Ns-Pog', characterizes the position of the lower lip $(\mathrm{mm})$;

distance Is-NCL (also known as: Upper Lip Protrusion and Ls-NsPog' by Roth-Jarabak) - the distance from the point Ls to the line Ns-Pog', characterizes the position of the upper lip $(\mathrm{mm})$;

Is-Olf distance (also known as: Max-Incisor Extrusion $1 \mathrm{u}-\mathrm{OcP}, \mathrm{Max}$. Incisor to Occl. Plane) - the distance between the point Is and the closing plane (POcp), characterizes the vertical location of the cutting edge of the medial incisor $(\mathrm{mm})$;

Overjet distance (CFT-Bjork analysis) - the distance from the point Is to li in the sagittal plane, characterizes the inter-cutter distance in the sagittal plane $(\mathrm{mm})$;

Wits distance (CFT-Bjork analysis) - the distance between the projections of points $A$ and $B$ on the closing plane (POcp), characterizes the linear ratio of the lower and upper jaws along the folding plane $(\mathrm{mm})$;

angle A-N-B (also known as: ss-n-sm, Jaw Relation) formed by lines A-N and N-B, characterizes the position of the jaws to each other $\left({ }^{\circ}\right)$;

angle A-N-Pog (also known as: ss-n-pg, Jaw Relation to Pog, NAPog, Angle of Convexity) - formed by lines A-N and N-Pog, characterizes the intermaxillary position in the sagittal plane $\left(^{\circ}\right)$;

CL/ML angle (also known as Mandibular alveolar prognathism) - formed by the lines Id-Pog and c-Me, characterizes the position of the mandibular cell sprout $\left({ }^{\circ}\right)$;

ILi/ML angle (also known as Mandibular incisor inclination) - formed by the central axis of the lower medial incisor and the line tGo-Me, characterizes the position of the lower medial incisor to the plane of the mandible $\left({ }^{\circ}\right)$;

ILs/ILi angle (also known as: Interincisal Angle according to Roth-Jarabak, inter-incision angle) - formed by the central axes of the upper and lower medial incisors, characterizes the inclination of the upper and lower medial incisors to each other $\left(^{\circ}\right)$;

angle ILs/NL (also known as: Max1-SpP Angle, Maxillary incisor inclination) - formed by the central axis of the upper 
medial incisor and the line SpP, characterizes the position of the upper medial incisor to the palatal plane $\left(^{\circ}\right)$;

angle ML/RL (also known as: Mand. Growth Zone 1, arGoMe, Jaw-/Gonial Angle) - formed by the lines Ar-tGo and tGo-Me, characterizes the angle of the lower jaw $\left({ }^{\circ}\right)$;

NL/ML angle (also known as: Jaw Relation, Vertical jaw Relationship, SpP-GoMe Angle) - formed by tGo-Me and $\mathrm{SpP}$ lines, characterizes the position of the closing plane to the palatal plane $\left({ }^{\circ}\right)$;

N-S-Ar angle (also known as: Growth Zone 1, NSar Angle, Sella-/Saddle Angle) - formed by N-S and S-Ar lines, characterizes the position of the temporomandibular joint $\left({ }^{\circ}\right)$;

N-S-Ba angle (also known as: Growth Zone 2, NSBa Angle) - formed by $\mathrm{N}-\mathrm{S}$ and $\mathrm{S}-\mathrm{Ba}$ lines, characterizes the angle of the skull base $\left({ }^{\circ}\right)$;

NSL/ML angle (also known as: Mand. Inclination, SNGoMe Angle, ML-NSL) - formed by lines S-N and tGo$\mathrm{Me}$, characterizes the inclination of the mandible to the anterior base of the skull $\left({ }^{\circ}\right)$;

NSL/NL angle (also known as: Max. Inclination, SNSpP Angle, NL-NSL) - formed by $\mathrm{S}-\mathrm{N}$ and SpP lines, characterizes the inclination of the upper jaw to the anterior base of the skull $\left({ }^{\circ}\right)$;

angle OLf/NSL (also known as: Occl. Plane Inclinatio, $\mathrm{SN}-\mathrm{OcP}$ Angle) - formed by lines $\mathrm{S}-\mathrm{N}$ and OcP, characterizes the position of the closing plane to the base of the skull $\left({ }^{\circ}\right)$; angle OLi/ML (also known as: Mand. Dental Zone, ML/ Oli, Mandibular zone, MeGo-OcP Angle) - formed by lines tGo-Me and OcP, characterizes the position of the closing plane to the mandibular plane $\left(^{\circ}\right)$;

angle OLs/NL (also known as: Max. Dental Zone, NL/ OLs, Maxillary zone, SpP-OcP Angle) - formed by the lines $\mathrm{SpP}$ and $\mathrm{OcP}$, characterizes the position of the closing plane to the palatal plane $\left({ }^{\circ}\right)$;

angle Pr-N-A (also known as: pr-n-ss, Maxillary alveolar prognathism) - formed by lines A-N and N-Pr, characterizes the position of the maxillary cell sprout $\left(^{\circ}\right)$;

angle S-N-A (also known as: Max. Protrusion, Maxillary prognatism, SNA Angle) - formed by the lines S-N and N-A, characterizes the position of the upper jaw in the sagittal plane $\left({ }^{\circ}\right)$;

angle S-N-B (also known as: Mand. Protrusion, Mandibular alveolar prognathism, SNB Angle) - formed by lines S-N and N-B, characterizes the position of the lower jaw in the sagittal plane $\left({ }^{\circ}\right)$;

S-N-Pog angle (CFT-Bjork analysis - Mand. Protrusion) - is formed by S-N and N-Pog lines, characterizes the position of the lower jaw in the sagittal plane $\left(^{\circ}\right)$;

ratio N-S:S-Ar' (Growth Zone $3 \mathrm{~N}-\mathrm{S}$ ) - the ratio of distances N-S and S-Ar', characterizes the position of the projection of the temporomandibular joint on the line N-S (unit).

The main cephalometric points and measurements according to the Roth-Jarabak method:

Ar-Go distance (also known as: Ramus Length, the length of the lower jaw branch) - the distance from the $\mathrm{Ar}$ point to the tGo point, which characterizes the length of the lower jaw branch $(\mathrm{mm})$;

distance Go_Me (also known as: Body (Mandibular) Length) - the distance from the point tGo to the point Me, characterizes the length of the body of the mandible $(\mathrm{mm})$;

Li-NsPog' distance (also known as: Facial aesthetic line Lower lip, Distance of Lower Lip to Esthetic Line) - the distance from the Li point to the Ns-Pog line, characterizes the position of the lower lip relative to the "Aesthetic line" the Ns-Pog' line $(\mathrm{mm})$.

distance Ls-NsPog' (also known as: Facial aesthetic line upper lip, Distance of Upper Lip to Esthetic Line) - the distance from the point Ls to the line Ns-Pog", characterizes the position of the upper lip relative to the "Aesthetic line" the line Ns-Pog' $(\mathrm{mm})$;

N-Go distance (also known as: Facial Depth, depth of the face) - the distance from the point $N$ to the point tGo, characterizes the height of the bony base of the face, and the actual distance of the chin from the point $\mathrm{N}$ in the vertical plane $(\mathrm{mm})$;

$\mathrm{N}-$ Me distance (also known as: Anterior Facial Height, anterior facial height) - the distance from the $\mathrm{N}$ point to the Me point, characterizes the anterior facial height, and the actual distance of the lower chin point Me from the $\mathrm{N}$ point $(\mathrm{mm})$;

distance N-S (also known as: Anterior Cranial Base Length) - the distance from point $\mathrm{N}$ to point $\mathrm{S}$, characterizes the length of the anterior base of the skull $(\mathrm{mm})$;

distance S-Ar (also known as: Posterial Cranial Base Length, Length of Lateral Cranial Base, posterior length of skull base, lateral length of skull base) - distance from point $S$ to point Ar, characterizes the location of the temporomandibular joint relative to the Turkish saddle $(\mathrm{mm})$;

distance S-Gn (also known as: Facial Length on Y Axis) - the distance from point $S$ to point $\mathrm{Gn}$, characterizes the length of the face determined by the $B$ axis, and the actual distance of the chin from the Turkish saddle $(\mathrm{mm})$;

S-Go distance (also known as: Posterior Facial Height) - the distance from the $S$ point to the tGo point, characterizes the posterior height of the face, and the actual distance of the mandibular angle from the Turkish saddle, also determines the degree of development of the mandibular branch mainly in the vertical plane $(\mathrm{mm})$;

1lo-NPog distance (also known as: Lower incisor to facial plane N-Po, Distance of Incisal Edge of 1 l to N-Pog) - the distance from the cutting edge of the lower medial incisor to the N-Pog line, characterizes the anteroposterior position of the lower medial incisor $(\mathrm{mm})$;

1up-NPog distance (also known as: Upper incisor to facial plane N-Po, Distance of Incisal Edge of $1 \mathrm{u}$ to N-Pog) - the distance from the cutting edge of the upper medial incisor to the N-Pog line, characterizing the anteriorposterior position of the upper median incisor $(\mathrm{mm})$;

angle A-N-B (also known as Angle ANB) - formed by 
lines $\mathrm{A}-\mathrm{N}$ and $\mathrm{N}-\mathrm{B}$, characterizes the intermaxillary ratio in the sagittal plane $\left({ }^{\circ}\right)$;

Ar-Go-Gn angle (also known as: Gonial Angle) - formed by the lines Ar-tGo and tGo-Gn, characterizes the value of the angle of the lower jaw $\left(^{\circ}\right)$;

angle II (also known as: Interincisal Angle) is formed by the central axes of the upper and lower medial incisors, characterizes the angular ratio of the medial incisors of the upper and lower jaws $\left({ }^{\circ}\right)$;

Mand1-GoMe angle (also known as: Lower incisor to Go-Gn, Angle of Axis of 1 to Mand. Plane) - formed by the central axis of the lower medial incisor and the line tGo-Me, characterizes the inclination of the lower medial incisor to the mandibular plane $\left({ }^{\circ}\right)$;

angle Max1-SN (also known as: 1to Sn, Angle of Axis of $1 \mathrm{u}$ to Anterior Cranial Base) - formed by the central axis of the upper medial incisor and the line $\mathrm{S}-\mathrm{N}$, characterizes the slope of the upper medial incisor to the anterior base of the skull $\left({ }^{\circ}\right)$;

N-A-Pog angle (also known as: Facial Convexity (NAPo), facial convexity angle) - formed by N-A and A-Pog lines, characterizing the convexity of the facial bone profile $\left({ }^{\circ}\right)$;

N-Go-Ar angle (also known as: Upper Gonial Angle) formed by the lines $\mathrm{N}-\mathrm{tGo}$ and $\mathrm{tGo}-\mathrm{Ar}$, characterizes the angle of inclination of the lower jaw branch to the line $\mathrm{N}$ tGo $\left({ }^{\circ}\right)$;

N-Go-Gn angle (also known as: Lower Gonial Angle) formed by the lines N-tGo and tGo-Gn, characterizes the angle of the mandible to the line $\mathrm{N}-\mathrm{tGo}\left({ }^{\circ}\right)$;

N-S-Ar angle (also known as: Saddle Angle) is formed by the N-S and S-Ar lines, characterizes the position of the temporomandibular joint $\left({ }^{\circ}\right)$;

angle N-S-Gn (also known as: $\mathrm{Y}$ Axis to $\mathrm{SN}$, angle In the axis) - formed by the lines N-S and S-tGn, characterizes the direction of the axis of development of the mandible $\left({ }^{\circ}\right)$;

OcP-GoGn angle (also known as: Oclusal plane to GGn, Angle of Mand. to Occl. Plane) - is formed by OcP and tGo-Me lines, characterizes the inclination of the closing plane to the mandibular plane $\left({ }^{\circ}\right)$;

S-Ar-Go angle (also known as: Articular Angle, joint angle) - formed by the lines S-Ar and Ar-tGo, characterizes the position of the temporomandibular joint and the branch of the mandible $\left({ }^{\circ}\right)$;

angle S-N-A (also known as Angle SNA) - formed by the lines $\mathrm{S}-\mathrm{N}$ and $\mathrm{N}-\mathrm{A}$, characterizes the position of the upper jaw in the boom plane $\left({ }^{\circ}\right)$;

angle S-N-B (also known as Angle SNB) - formed by the lines $\mathrm{S}-\mathrm{N}$ and $\mathrm{N}-\mathrm{B}$, characterizes the position of the lower jaw in the boom plane $\left({ }^{\circ}\right)$;

angle SN-GoGn (also known as: Angle of Anterior Cranial Base to Mand. Plane) - formed by the lines SN and tGo-Gn, characterizes the inclination of the lower jaw to the anterior base of the skull $\left({ }^{\circ}\right)$;

S-N-Pog angle (also known as: Facial Plane (N-Po), face angle) - formed by S-N and N-Pog lines, characterizes the position of the lower jaw, namely the bony chin in the sagittal plane $\left({ }^{\circ}\right)$;

Sum - the sum of the angles N-S-Ar, S-Ar-Go and Ar-Go$\mathrm{Gn}$, characterizes the direction of development (vertical when increasing and horizontal when decreasing) of the lower jaw $\left(^{\circ}\right)$;

the ratio of Go_Me:N-S - the ratio of the distances Go_Me and N-S, allows you to estimate the degree of development of the lower jaw relative to the anterior base of the skull (\%);

the ratio of S-Ar:Ar-Go - the ratio of the distances S-Ar and Ar-Go, allows you to assess the degree of development of the branch of the mandible relative to its body (\%);

S-Go:N-Me ratio - the ratio of S-Go and N-Me distances, characterizes the ratio between the front and rear face heights (\%).

It should be noted that, unlike the original Jarabak analysis, the Roth-Jarabak analysis does not use a specific A-point which is placed $2 \mathrm{~mm}$ in front of the apex of the middle maxillary incisor, but uses the more common Downs A-point.

Indicators in this study were divided into three groups according to Dmitriev M. O. [10]. The first group includes metric characteristics of the skull, which are used as basic indicators in the methods of cephalometric analysis; to the second group - dental-maxillary in which the skeleton has already been formed and which surgical methods can change the length, width, angles and positions of the upper and lower jaws; to the third group - indicators that actually characterize the position of each individual tooth relative to each other, cranial structures and the profile of the soft tissues of the face.

Committee on Bioethics of National Pirogov Memorial Medical University, Vinnytsya (Minutes № 8 of 18.10.2019.) It is established that the studies meet the bioethical and moral requirements of the Declaration of Helsinki, the Council of Europe Convention on Human Rights and Biomedicine (1977), the relevant provisions of the WHO and the laws of Ukraine.

Correlation assessment was performed in the license package "Statistica 6.0" using the non-parametric Spearman method.

\section{Results}

The results of the evaluation of the correlations between the indicators of the first group by the method of CFT-Bjork or Roth-Jarabak with the indicators of the second and third groups are presented in tables 1 and 2.

\section{Discussion}

Manifestations of sexual dimorphism were detected in the study of teleradiograms by the Bjork-Jarabak method of 100 people living in Bangladesh. According to the analysis of the data, men have in comparison with women the values of the saddle angle, gonial angle, body length of the lower jaw, incisor angle and anterior height of the face. In general, it was also found that the indicators for both 
Table 1. Correlations of the first group of indicators according to the CFT-Bjork method (names of indicators without color selection) with the second (names of indicators are highlighted in light gray) and the third (names of indicators are highlighted in dark gray) groups.

\begin{tabular}{|c|c|c|c|c|c|c|}
\hline \multirow{2}{*}{ Indexes } & \multicolumn{3}{|c|}{ Young men } & \multicolumn{3}{|c|}{ Young women } \\
\hline & N-S-Ar & N-S-Ba & N-S:S-Ar' & N-S-Ar & N-S-Ba & N-S:S-Ar' \\
\hline S-N-A & -0.27 & -0.25 & 0.19 & -0.44 & -0.36 & 0.38 \\
\hline S-N-Pog & -0.43 & -0.39 & 0.32 & -0.43 & -0.40 & 0.33 \\
\hline S-N-B & -0.43 & -0.38 & 0.35 & -0.40 & -0.36 & 0.30 \\
\hline A-N-Pog & 0.24 & 0.17 & -0.20 & -0.02 & 0.05 & 0.04 \\
\hline A-N-B & 0.26 & 0.20 & -0.24 & -0.11 & -0.06 & 0.12 \\
\hline NSL/NL & 0.25 & 0.18 & -0.01 & 0.42 & 0.37 & -0.34 \\
\hline NSL/ML & 0.29 & 0.26 & -0.23 & 0.39 & 0.39 & -0.33 \\
\hline NL/ML & 0.21 & 0.23 & -0.27 & 0.10 & 0.13 & -0.13 \\
\hline li-Is & 0.12 & 0.01 & -0.14 & -0.14 & -0.08 & 0.14 \\
\hline ML/RL & -0.06 & -0.06 & -0.02 & 0.18 & 0.17 & -0.19 \\
\hline Pr-N-A & 0.11 & 0.16 & -0.11 & -0.02 & -0.02 & 0.01 \\
\hline CL/ML & 0.14 & 0.12 & -0.08 & 0.00 & 0.03 & 0.01 \\
\hline ILs/NL & -0.21 & -0.11 & 0.24 & 0.13 & 0.13 & -0.13 \\
\hline ILi/ML & 0.17 & 0.15 & -0.17 & -0.11 & -0.13 & 0.18 \\
\hline ILs/ILi & -0.08 & -0.11 & 0.15 & 0.00 & -0.01 & -0.03 \\
\hline Overjet & 0.11 & 0.16 & -0.13 & -0.11 & -0.08 & 0.14 \\
\hline Wits & 0.20 & 0.11 & -0.21 & -0.15 & -0.12 & 0.15 \\
\hline OLs/NL & 0.33 & 0.30 & -0.35 & 0.06 & 0.07 & -0.08 \\
\hline OLi/ML & -0.04 & -0.05 & -0.06 & 0.06 & 0.12 & -0.10 \\
\hline OLf/NSL & 0.35 & 0.35 & -0.26 & 0.45 & 0.42 & -0.41 \\
\hline Is-OLf & 0.23 & 0.14 & -0.07 & -0.06 & -0.01 & 0.08 \\
\hline Is-NCL & 0.19 & 0.21 & -0.08 & -0.10 & -0.05 & 0.19 \\
\hline li-NCL & 0.10 & 0.14 & -0.03 & -0.01 & 0.06 & 0.08 \\
\hline
\end{tabular}

Notes: here and in the following table, significant direct weak correlations are highlighted in yellow; red color accurate direct medium strength correlation; the significant inverse mean correlations are highlighted in blue.

men and women differed significantly from the normative indicators for Bjork-Jarabak [3].

Differences in cephalometric parameters according to Bjork-Jarabak were found for the population of Saudi Arabia. Thus, the largest differences were found for the length of the anterior and posterior part of the face, the height of the branch and the length of the mandible, the length of the anterior and posterior cranial part [4].

Jarabak cephalometric standards have been established for Pakistanis. Differences with the control sample were found for such indicators as upper and lower gonial angle, saddle angle $(p<0.001)$, anterior facial height, posterior facial height, anterior and posterior skull base $(p<0.05)$ [17].

In another study conducted on a Pakistani sample of individuals, however, using Bjork-Jarabak analyzes, the authors found no differences among virtually all indicators except joint angle and PFH/AFH ratio [20].

Features of cephalometric indicators according to Jarabak are established for the population of Nepal. Statistically significant differences were found for 10 of the 30 studied indicators. In addition, manifestations of sexual dimorphism were detected for 11 of the 30 studied parameters [24].

Processing of cephalometric analysis data by Bjork 122 Polish adolescents revealed the relationship between odontometric parameters and indicators of facial soft tissues [19].

P. Vasanthan and others [28] estimated the height of teeth in malocclusions using cephalometric analysis by Bjork. To conduct this work, the authors analyzed the indicators before and after treatment. Statistically significant results were obtained for the height of the teeth of the mandible measured from the plane of the mandible and the plane CSm.

Interdependencies between cranial structures and odontometric parameters using cephalometric analysis by Downs, Steinner, Bjork, Ricketts and McNamara were found when working with the Brazilian population sample $[7,18]$.

A correlation between Bjork growth rates and skeletal model prediction was found by Davidovitch $\mathrm{M}$. and coauthors [9]. It was found that only LAFH correlated with age in all study groups.

In the analysis of multiple correlations of the first group of indicators according to the CFT-Bjork method (values of N-S-Ar and N-S-Ba angles and the ratio N-S:S-Ar') with the second group of indicators in both $\mathrm{YM}$ and $\mathrm{YW}$, reliable mean inverse values were established of the magnitude of the angles N-S-Ar and N-S-Ba ( $r=$ from -0.38 to -0.43 in $\mathrm{YM}$ and $\mathrm{r}=$ from -0.36 to -0.43 in $\mathrm{YW}$ ) and reliable mediumstrength direct correlations of the ratio N-S:S-Ar' ( $r=0.32$ and 0.35 in $\mathrm{YM}$ and $r=0.30$ and 0.33 in $\mathrm{YW}$ ) with the value of the angles S-N-Pog and S-N-B; and only in $Y W$ - reliable medium-strength feedback of the magnitude of the angles $\mathbf{N}-\mathbf{S}-\mathbf{A r}$ and $\mathbf{N}-\mathbf{S}-\mathbf{B a}(r=-0.36$ and -0.44$)$ and reliable average-strength direct correlations of the ratio $\mathbf{N}-\mathbf{S}: \mathbf{S}-\mathbf{A r}^{\prime}$ $(r=0.38)$ with the value of the angle $\mathbf{S}-\mathbf{N}-\mathbf{A}$, as well as reliable average strength direct correlations of the values of the angles N-S-Ar and N-S-Ba ( $r=$ from 0.37 to 0.42$)$ and reliable average strength feedback of the ratio N-S:S-Ar' $(r$ $=-0.33$ and -0.34 ) with the value of the angles NSL/NL and NSL/ML.

In the analysis of multiple correlations of the first group of indicators by the CFT-Bjork method with the third group of indicators in $Y M$, only reliable medium-strength direct correlations between the magnitude of the angles N-S-Ar and $\mathbf{N}-\mathbf{S}-\mathrm{Ba}$ ( $r=$ from 0.30 to 0.35 ) with the magnitude of the angles OLs/NL and OLf/NSL, as well as a significant average feedback of the ratio N-S:S-Ar' $(r=-0.35)$ with the value of the angle OLs/NL; and in $Y W$ - only reliable medium-strength direct correlations of the magnitude of the angles N-S-Ar and N-S-Ba $(r=0.42$ and 0.45$)$, as well 
Vakhovskyi V. V., Shinkaruk-Dykovytska M. M., Pogorila A. V., Likhitskyi O. O., Gunas I. V.

Table 2. Correlations of the first group of indicators according to the Roth-Jarabak method (names of indicators without color selection) with the second (names of indicators are highlighted in light gray) and the third (names of indicators are highlighted in dark gray) groups.

\begin{tabular}{|c|c|c|c|c|c|c|c|c|c|c|}
\hline \multirow{2}{*}{ Indexes } & \multicolumn{5}{|c|}{ Young men } & \multicolumn{5}{|c|}{ Young women } \\
\hline & N-S-Ar & N-S & S-Ar & Ar-Go & S-Ar:Ar-Go & N-S-Ar & N-S & S-Ar & Ar-Go & S-Ar:Ar-Go \\
\hline S-Ar-Go & -0.60 & -0.07 & -0.06 & -0.35 & 0.22 & -0.69 & 0.19 & 0.08 & -0.04 & 0.06 \\
\hline Ar-Go-Gn & -0.06 & -0.32 & 0.04 & -0.50 & 0.42 & 0.19 & -0.09 & -0.14 & -0.42 & 0.19 \\
\hline Sum & 0.27 & -0.48 & -0.23 & -0.65 & 0.37 & 0.41 & -0.17 & -0.31 & -0.47 & 0.12 \\
\hline N-Go-Ar & -0.02 & 0.28 & 0.27 & -0.04 & 0.16 & 0.09 & 0.12 & 0.06 & -0.33 & 0.26 \\
\hline N-Go-Gn & -0.04 & -0.59 & -0.07 & -0.61 & 0.43 & 0.16 & -0.21 & -0.19 & -0.32 & 0.10 \\
\hline Go_Me & 0.19 & 0.51 & 0.09 & 0.41 & -0.29 & 0.02 & 0.40 & 0.36 & 0.34 & 0.03 \\
\hline Go_Me:N-S & 0.30 & 0.02 & -0.04 & 0.29 & -0.24 & 0.26 & -0.32 & 0.09 & 0.19 & -0.06 \\
\hline S-N-A & -0.27 & 0.20 & 0.16 & 0.51 & -0.30 & -0.44 & -0.13 & 0.08 & 0.10 & -0.05 \\
\hline S-N-B & -0.43 & 0.25 & 0.13 & 0.53 & -0.35 & -0.40 & -0.10 & 0.11 & 0.21 & -0.12 \\
\hline A-N-B & 0.22 & -0.10 & -0.05 & -0.07 & 0.06 & -0.09 & -0.08 & -0.03 & -0.10 & 0.05 \\
\hline SN-GoGn & 0.27 & -0.48 & -0.23 & -0.65 & 0.37 & 0.41 & -0.17 & -0.31 & -0.47 & 0.12 \\
\hline N-Go & 0.30 & 0.46 & 0.35 & 0.47 & -0.16 & -0.01 & 0.56 & 0.46 & 0.59 & -0.06 \\
\hline S-Gn & -0.11 & 0.28 & 0.38 & 0.24 & -0.01 & -0.25 & 0.56 & 0.42 & 0.36 & 0.05 \\
\hline N-S-Gn & 0.40 & -0.50 & -0.12 & -0.49 & 0.35 & 0.50 & -0.23 & -0.14 & -0.20 & 0.08 \\
\hline S-Go & -0.13 & 0.29 & 0.48 & 0.71 & -0.23 & -0.35 & 0.36 & 0.56 & 0.74 & -0.10 \\
\hline N-Me & 0.24 & -0.04 & 0.26 & -0.11 & 0.24 & 0.11 & 0.41 & 0.29 & 0.24 & 0.06 \\
\hline S-Go:N-Me & -0.31 & 0.36 & 0.29 & 0.66 & -0.33 & -0.42 & 0.11 & 0.41 & 0.54 & -0.09 \\
\hline S-N-Pog & -0.44 & 0.32 & 0.22 & 0.50 & -0.29 & -0.41 & -0.04 & 0.16 & 0.26 & -0.11 \\
\hline N-A-Pog & 0.21 & -0.15 & -0.13 & -0.08 & 0.04 & 0.00 & -0.16 & -0.12 & -0.16 & 0.02 \\
\hline OcP-GoGn & -0.03 & -0.29 & 0.02 & -0.52 & 0.35 & 0.12 & -0.11 & -0.17 & -0.29 & 0.10 \\
\hline II & -0.08 & -0.17 & -0.08 & -0.33 & 0.22 & 0.00 & -0.03 & -0.04 & 0.15 & -0.15 \\
\hline Max1-SN & -0.25 & 0.27 & 0.15 & 0.47 & -0.31 & -0.14 & 0.01 & 0.13 & 0.08 & 0.03 \\
\hline Mand1-GoMe & 0.17 & 0.31 & 0.06 & 0.48 & -0.33 & -0.11 & 0.18 & 0.12 & 0.13 & 0.00 \\
\hline 1up-NPog & 0.24 & -0.10 & -0.14 & 0.12 & -0.14 & 0.02 & -0.11 & -0.06 & -0.27 & 0.13 \\
\hline 1lo-NPog & 0.19 & -0.20 & -0.17 & 0.04 & -0.10 & 0.07 & -0.12 & -0.14 & -0.24 & 0.06 \\
\hline Ls-NsPog' & 0.18 & 0.05 & -0.14 & 0.03 & -0.06 & -0.11 & -0.11 & -0.18 & -0.23 & 0.02 \\
\hline Li-NsPog' & 0.07 & -0.09 & -0.20 & 0.02 & -0.08 & -0.01 & -0.11 & -0.11 & -0.33 & 0.13 \\
\hline
\end{tabular}

Notes: significant direct strong correlations are highlighted in magenta; significant inverse weak correlation forces are highlighted in green; significant inverse strong correlations are highlighted in purple.

as reliable average-strength feedback of the ratio $\mathbf{N}-\mathbf{S}: \mathbf{S}$ $\operatorname{Ar}^{\prime}(r=-0.41)$ with the value of the angle OLf/NSL.

Our quantitative analysis of significant correlations in Ukrainian YM and YW with orthognathic occlusion between the characteristics of the basal cranial structures (first group) by CFT-Bjork with teleradiographic parameters of the upper and lower jaws (second group) and the location of teeth (third group) revealed the following distribution correlations:

with indicators of the second group - YM have 7 correlations out of 30 possible (23.3\%), of which, $6.7 \%$ of direct medium strength and $3.3 \%$ of direct weak force and $13.3 \%$ of reverse medium force; $\mathrm{YW}$ have 15 correlations out of 30 possible $(50.0 \%$ ), of which $23.3 \%$ are direct medium strength and $26.7 \%$ are reverse medium strength; with indicators of the third group - YM have 5 correlations out of 39 possible (12.8\%), of which, $10.3 \%$ are direct medium strength and $2.6 \%$ are reverse medium strength; YW have 3 correlations out of 39 possible $(7.7 \%)$, of which $5.1 \%$ are direct medium strength and $2.6 \%$ reverse medium strength.

In the analysis of multiple correlations of the first group of indicators by the Roth-Jarabak method (the value of the angle N-S-Ar, the distances N-S, S-Ar and Ar-Go and the ratio S-Ar:Ar-Go) with the second group of indicators in $Y M$ found reliable, mostly average forces, direct and feedback correlations of values of Ar-Go distances ( $r=$ from 0.29 to 0.71 and $r=$ from -0.35 to -0.65 ) and $N-S$ ( $r=$ from 0.28 to 
0.51 and $r=$ from -0.32 to -0.59$)$ and the ratio of S-Ar:Ar-Go ( $r=$ from 0.35 to 0.43 and $r=$ from -0.29 to -0.35 ) with most indicators of the second group, also only direct, mostly medium-strength ( $r=$ from 0.29 to 0.48 ) correlations of distances S-Ar with the value of distances N-Go, S-Gn and S-Go and the ratio S-Go:N-Me; and in YW - reliable, mostly of medium strength inverse, correlations ( $r=$ from -0.25 to 0.69) of the value of the angle N-S-Ar with almost half of the indicators of the second group, as well as reliable, mostly of medium strength direct, correlations of distances S-Ar $(r=$ from 0.29 to 0.56 ) and $\mathbf{N}-\mathbf{S}$ ( $r=$ from 0.36 to 0.56 ) with almost half of the indicators of the second group and reliable, mostly medium-strength, direct and feedback correlations of ArGo distances ( $r=$ from 0.24 to 0.74 and $r=$ from -0.32 to 0.47 ) with most indicators of the second group.

In the analysis of multiple correlations of the first group of indicators according to the Roth-Jarabak method with the third group of indicators in $Y M$, only reliable average strength direct $(r=0.47$ and 0.48$)$ and average strength inverse $(r=-0.33$ and -0.52$)$ correlations of the distance Ar-Go with the magnitude of the angles Max1-SN and Mand1-GoMe (straight) and the magnitude of the angles OcP-GoGn and II (reverse) and vice versa, the significant mean strength of the inverse $(r=-0.31$ and -0.33$)$ and the average strength direct $(r=0.35)$ correlation of the ratio SAr:Ar-Go with the magnitude of the angles Max1-SN and Mand1-GoMe (reverse) and the magnitude of the angle OcP-GoGn (direct); and in YW - only reliable, mostly weak force, inverse ( $r=$ from -0.23 to -0.33 ) correlations of the value of the distance Ar-Go with the value of the angle OcP. GoGn and the value of the distances 1 up-NPog, 1lo-NPog, Ls-NsPog' and Li-NsPog'.

Our quantitative analysis of significant correlations in Ukrainian YM and YW with orthognathic occlusion between the indicators of the characteristics of basal cranial structures (first group) by Roth-Jarabak method with teleradiographic parameters of the upper and lower jaws

\section{References}

[1] Afify, A. R., \& Zawawi, K. H. (2012). The prevalence of dental anomalies in the Western region of Saudi Arabia. International Scholarly Research Notices, 2012, 837270. doi: 10.5402/ 2012/837270.

[2] Alabdullah, M., Saltaji, H., Abou-Hamed, H., \& Youssef, M. (2015). Association between facial growth pattern and facial muscle activity: A prospective cross-sectional study. International orthodontics, 13(2), 181-194. doi: 10.1016/j.ortho.2015.03.011

[3] Alam, M. K., Basri, R., Purmal, K., Sikder, M. A., Saifuddin, M., \& lida, J. (2012). Determining cephalometric norms for Bangladeshi adult using Bjork-Jarabaks' analysis. International Medical Journal, 19(4), 329-332.

[4] Alshahrani, I., Kamran, M. A., Alhaizaey, A., \& Abumelha, N. (2018). Evaluation of skeletal variations and establishment of Cephalometric Norms in Saudi Sub Population using Bjork Jarabak's analysis. Pakistan journal of medical sciences, 34(5), 1104-1109. doi: 10.12669/pjms.345.15556

[5] Björk, A. (1966). Sutural growth of the upper face studied by the implant method. Acta Odontologica Scandinavica, 24(2), 109-127. doi: 10.3109/00016356609026122 (second group) and the location of teeth (third group) revealed the following distribution correlations:

with indicators of the second group - in YM 46 correlations from 95 possible (48.4\%), from which, $2.1 \%$ of direct strong, $21.1 \%$ of direct average force and $4.2 \%$ of direct weak force and $4.2 \%$ of return strong, $14.7 \%$ of return of average force and $2.1 \%$ of weak force reversals; $Y W$ have 39 correlations out of 95 possible $(41.1 \%)$, of which, $1.1 \%$ direct strong, $17.9 \%$ direct medium strength and $5.3 \%$ direct weak force and $1.1 \%$ reverse strong, $13.7 \%$ reverse medium strength and $2.1 \%$ reverse weak force ;

with indicators of the third group - in YM 9 correlations out of 40 possible $(22.5 \%)$, of which, $10.0 \%$ of direct medium strength, $10.0 \%$ of reverse of medium strength and $2.5 \%$ of reverse of weak strength; YW have only 5 correlations out of 40 possible (12.5\%), of which, $10.0 \%$ are weak-strength and $2.5 \%$ are moderate-strength.

Thus, the established features of correlations of characteristics of basal cranial structures determined by CFT-Bjork and Roth-Jarabak methods with teleradiographic parameters of the upper and lower jaws and the location of teeth in Ukrainian YM and YW with orthognathic occlusion will allow more reasonable and correct interpretation of the data. teleradiograms by these methods.

\section{Conclusion}

1. In Ukrainian YM and YW with orthognathic occlusion, qualitative and quantitative features of correlations of characteristics of basal cranial structures determined by CFT-Bjork and Roth-Jarabak methods with teleradiographic parameters of upper and lower jaws and tooth location were established.

2. Manifestations of sexual dimorphism of correlations between the indicators determined by the methods of CFTBjork and Roth-Jarabak both in number and strength, and in the direction of correlations was established.

[6] Bushan, M. H., Vasylenko, Z. S., \& Hryhoreva, L. P. (1990). Справочник по ортодонти [Handbook of orthodontics]. Кишенев: Картя Молдовеняскэ - Kishinev: Kartia Moldoveniaske.

[7] Cardoso, R., Ajzen, S., Andriolo, A. R., Oliveira, J. X. D., \& Andriolo, A. (2012). Analysis of the cephalometric pattern of Brazilian achondroplastic adult subjects. Dental Press Journal of Orthodontics, 17, 118-129. doi: 10.1590/S217694512012000600023

[8] Cassetta, M., Altieri, F., Giansanti, M., Di-Giorgio, R., \& Calasso, S. (2014). Morphological and topographical characteristics of posterior supernumerary molar teeth: an epidemiological study on 25,186 subjects. Medicina oral, patologia oral y cirugia bucal, 19(6), e545-549. doi: 10.4317/medoral.19775

[9] Davidovitch, M., Eleftheriadi, I., Kostaki, A., \& Shpack, N. (2016). The use of Bjork's indications of growth for evaluation of extremes of skeletal morphology. European journal of orthodontics, 38(6), 555-562. doi: 10.1093/ejo/cjv084

[10] Dmitriev, М.О.(2017). Зв'язки основних краніальних показників з характеристиками положення зубів верхньої і ниж- 
ньої щелеп та профрілем м'яких тканин обличчя в юнаків і дівчат [Relations of key cranial indicators with the characteristics of the teeth of the upper and lower jaws and profile face soft tissue in boys and girls]. Вісник морфологіï - Reports of Morphology, 23(1), 125-131.

[11] Dmitriev, M., Gunas, V., Polishchuk, S., Olkhova, I., \& Kumar, A (2020). Modeling of Central Incisors Position Indicators in boys and girls according to CC. Steiner method for Forensic Dental Identification. The Official Publication of Indian Academy of Forensic Medicine, 42(3), 155-160. doi: 10.5958/09740848.2020.00043.3

[12] Doroshenko, S. I., \& Kulginsky, E. А. (2007). Основы телерентеенографрии [Fundamentals of teleradiography]. К.: Здоров'я - K.: Zdorovija.

[13] Gracco, A. L., Zanatta, S., Valvecchi, F. F., Bignotti, D., Perri, A., \& Baciliero, F. (2017). Prevalence of dental agenesis in a sample of Italian orthodontic patients: an epidemiological study. Progress in orthodontics, 18(1), 1-7. doi: 10.1186/s40510017-0186-9

[14] Gunas, V. I., Kotsyura, O. O., Babych, L. V., Shevchuk, Y. G., \& Cherkasova, O. V. (2020). Features correlations of the sizes of molars with cephalometric indicators of men of the western region of Ukraine. Reports of Morphology, 26(2), 51-61. doi: 10.31393/morphology-journal-2020-26(2)-08

[15] Jarabak, J. R., \& Fizzell, J. A. (1972). Technique and treatment with light-wire edgewise appliances, ed. 2, St. Louis,, The CV Mosby Company. ISBN 9780801624292

[16] Kapdan, A., Kustarci, A., Buldur, B., Arslan, D., \& Kapdan, A. (2012). Dental anomalies in the primary dentition of Turkish children. European journal of dentistry, 6(2), 178-183. doi: 10.1055/s-0039-1698948

[17] Khan, T., Ahmed, I., \& Erum, E. G. (2013). Cephalometric measurements of a Pakistani adult sample according to Jarabak's Analysis. J Pak Med Assoc, 63, 1345-1348.

[18] Lenza, M. A., Carvalho, A. A. D., Lenza, E. B., Lenza, M. G., Torres, H. M. D., \& Souza, J. B. D. (2015). Radiographic evaluation of orthodontic treatment by means of four different cephalometric superimposition methods. Dental press journal of orthodontics, 20, 29-36. doi: 10.1590/2176-9451.20.3.029036.oar

[19] Loster, J. E., Williams, S., Wieczorek, A., \& Loster, B. W. (2015). The Polish face in profile: a cephalometric baseline study. Head \& face medicine, 11(1), 1-14. doi: 10.1186/s13005-0150065-x

[20] Malik, H., Afridi, S. K., Kamran, M. A., Mahroof, V., Alam, M. K.,
\& Qamruddin, I. (2017). A Cephalometric Analysis for Pakistani Adults Using Jarabak Bjork's Analysis. International medical journal, 24(1), 128-131.

[21] Marchenko, A. V., Shinkaruk-Dykovytska, M. M., Pozur, T. P., Gunas, V. I., \& Orlovskiy, V. O. (2020). Models of individual linear dimensions necessary for the construction of the correct form of dental arches in young men with a wide face, depending on the features of odontometric and cephalometric indicators. Wiadomosci lekarskie (Warsaw, Poland: 1960), 73(6), 11031107. PMID: 32723934

[22] Nielsen, I. L. (2011). Cephalometric morphological analysis: What information does it give you?. International orthodontics, 9(3), 316-324. doi: 10.1016/j.ortho.2011.06.003

[23] Phulari, B. (2013). An atlas on cephalometric landmarks. JP Medical Ltd. doi: 10.5005/jp/books/11877

[24] Pokharel, M., \& Shrestha, S. L. (2019). Cephalometric evaluation of Brahmins of Kathmandu, Nepal based on Jarabak's analysis. Journal of Kathmandu Medical College, 8(1), 13-19. doi: 10.3126/jkmc.v8i1.25263

[25] Rodriguez-Cardenas, Y. A., Arriola-Guillen, L. E., \& Flores-Mir, C. (2014). Bjork-Jarabak cephalometric analysis on CBCT synthesized cephalograms with different dentofacial sagittal skeletal patterns. Dental press journal of orthodontics, 19, 46-53. doi: 10.1590/2176-9451.19.6.046-053.oar

[26] Shetty, P., Adyanthaya, A., Adyanthaya, S., \& Sreelatha, S. V. (2012). The prevalence of hypodontia and supernumerary teeth in 2469 school children of the Indian population: an epidemiological study. Indian Journal of Stomatology, 3(3), 150-152.

[27] Sobon, J. S., Cherkasova, O. V., Gunas, V. I., Babych, L. V., \& Kotsyura, O. O. (2020). Correlations of linear sizes of molars with cephalometric indicators of practically healthy men of the southern region of Ukraine. Biomedical and Biosocial Anthropology, (38), 36-46. doi: 10.31393/bba38-2020-06

[28] Vasanthan, P., Mohan, J., Sabarinathan, J., Sabitha, S., \& Jeeva, S. J. (2018). Evaluation of Mandibular Dental Height Using Stable Structure of Bjork-A Comparative Cephalometric study. Journal of Advanced Medical and Dental Sciences Research, 6(11), 1-4. doi: 10.21276/jamdsr

[29] Vibhute, A. H., Vibhute, N. A., \& Daule, R. (2013). Prevalence of dental anomalies in pretreatment orthodontic patients in Western Maharashtra, India: An epidemiological study. Journal of orthodontic research, 1(2), 66-69. doi: 10.4103/23213825.116286 